\title{
Comparison of Early Versus Delayed Oral Feeding After Total Laryngectomy in Terms of Pharyngocutaneous Fistula Development
}

\author{
Suphi Bulğurcu ${ }^{1}$ (1) İbrahim Çukurova ${ }^{2}$ (1) \\ Original Investigation $\quad{ }^{1}$ Department of Otorhinolaryngology, Sultan Abdülhamid Han Training and Research Hospital, İstanbul, Turkey \\ ${ }^{2}$ Department of Otorhinolaryngology, Tepecik Training and Research Hospital, İzmir, Turkey
}

Abstract

ORCID IDs of the authors:

S.B. 0000-0002-0769-0513; i.Ç. 0000-0002-2398-3391.

Cite this article as: Bulğurcu S, Çukurova i. Comparison of Early Versus Delayed Oral Feeding After Total Laryngectomy in Terms of Pharyngocutaneous Fistula Development. Turk Arch Otorhinolaryngol 2018; 56(4):217-20.

\section{Corresponding Author:}

Suphi Bulğurcu; suphibulg@yahoo.com

Received Date: 09.06.2018

Accepted Date: 06.08 .2018

Available Online Date: 25.12.2018

(c) Copyright 2018 by Official Journal of the Turkish Society of Otorhinolaryngology and Head and

Neck Surgery Available online at

www.turkarchotolaryngol.net

DOI: 10.5152/ta0.2018.3605
Objective: There is still no consensus on the effect of early oral feeding and nasogastric tube feeding on the development of pharyngocutaneous fistula (PCF) after total laryngectomy. The aim of the present study was to compare the effects of early oral feeding and nasogastric tube (NGT) feeding after total laryngectomy on the incidence of PCF.

Methods: A total of 59 male and three female patients with a mean age of 61.65 (range 44-77) years who underwent total laryngectomy and bilateral neck dissection between May 2010 and June 2016 were evaluated retrospectively. Thirty-two patients started oral feeding on postoperative day three, and $30 \mathrm{pa}-$ tients started NGT feeding on postoperative day one following oral feeding on 7th day. Besides the investigation of the factors which can affect PCF formation, the incidence of PCF was also determined between the two groups of patients.

Results: Only preoperative albumin value was different between the groups in the determination of factors which can affect development of PCF. No statistical difference was found between the two groups in terms of the development of PCF and the length of hospital stay $(\mathrm{p}>0.05)$.

Conclusion: To start oral feeding on postoperative day three or with a NGT feeding on postoperative day one following oral feeding on day seven did not affect the development of PCF and the length of hospital stay in patients who underwent total laryngectomy.

Keywords: Laryngectomy, fistula, enteral nutrition, nasogastric tube

\section{Introduction}

The connection that forms between the pharynx and cervical skin is called a pharyngocutaneous fistula (PCF). This connection can cause leakage of saliva to the skin surface. This salivary leak on the skin is one the most common regional complications with a risk of $8 \%-22 \%$ after total laryngectomy. A PCF can result in a longer hospital stay, delay adjuvant postoperative treatment, and contribute to nutritional deficits and other life-threatening complications (1).

Many risk factors cause PCF, including comorbid illnesses, preoperative radiation treatment, former tracheotomy, hemoglobin level, patient age, tumor stage, type of operation, and concurrent neck dissection (2). However, no consensus exists to determine high-risk patients, as the same factors are not significant in all studies.
Adequate nutrition is an important part of postoperative management after total laryngectomy, but it is widely accepted that early oral feeding $(\mathrm{OF})$ may facilitate the development of PCF. Feeding via a nasogastric tube (NGT) for 7-14 days after total laryngectomy is a common practice applied by head and neck surgeons. On the contrary, there are also studies indicating that early $\mathrm{OF}$ does not contribute to PCF (3). However, there is still no consensus for the proper time to start oral intake. The aim of the present study was to investigate the effect of OF and NGT feeding on PCF formation in patients who underwent total laryngectomy for laryngeal carcinoma.

\section{Methods}

A total of 62 patients who were diagnosed with squamous cell carcinoma and underwent total laryngectomy with a bilateral neck dissection 
between May 2010 and June 2016 were retrospectively investigated after obtaining approval from the Ethics Committee of Tepecik Training and Research Hospital (Date 7/03/2017, No:2/7). All participants were informed about the study, and written informed consents were obtained. A transglottic carcinoma was found in 55 patients, and a subglottic carcinoma was present in 7 patients. Feeding was achieved with a NGT in 30 patients and with an OF in 32 patients. Total laryngectomy and bilateral neck dissection were performed with a " $\mathrm{T}$ " shaped closure technique in all patients.

A database was created including data about tumor features ( $\mathrm{T}$ and $\mathrm{N}$ stages), gender, age, smoking habits, alcohol use, presence of preoperative tracheostomy, preoperative radiotherapy, comorbidities (history of diabetes, chronic obstructive pulmonary disease, and vascular disease), blood values (preoperative serum hemoglobin, albumin, postoperative serum hemoglobin, and thrombocytes), and transfusion of erythrocytes.

Enteral nutrition with NGT was initiated in all patients on postoperative first day. The NGT was removed, and OF was started if no PCF had developed by postoperative day seven. In the non-NGT patients, nutritional support was provided with total parenteral nutrition products on postoperative first two days, and OF was started with semi-solid food on day three. OF with solid food was started on day seven if no PCF had developed. Nutritional support was provided with total parenteral nutrition products when a $\mathrm{PCF}$ was observed. All patients diagnosed with a PCF were treated daily with compressive dressings and adequate antibiotics. Patients who underwent thyroidectomy and partial laryngectomy, were reconstructed with a flap, or had tumor continuity at the surgical margin were excluded from the study.

Data were analyzed using the Statistical Package for the Social Sciences $\left(\right.$ SPSS $^{\circledR}$ ) version 20.0 software (IBM Corp.; Armonk, NY, USA). Pearson's chi-square test and Fisher's exact test were used to determine the associations between the study groups. Student's t-test was used to evaluate the duration of hospitalization. A p-value $<0.05$ was considered significant.

\section{Results}

No significant differences were observed in terms of age, gender, smoking and alcohol use, tumor $\mathrm{T}$ and $\mathrm{N}$ stages, preoperative serum hemoglobin, postoperative serum hemoglobin, thrombocytes, preoperative tracheostomy, preoperative radiotherapy, comorbid illnesses, or erythrocyte transfusions between the NGT and OF patients. The difference on preoperative albumin levels were statistically significant between the two groups (Table 1). However, no significant differences were observed between the two groups in terms of developing a PCF or hospital stay (Table 2). All patients with a PCF were treated with compressive dressings. All patients recovered completely without any sequela.

\section{Discussion}

Many studies have been conducted about prevention of PCF after total laryngectomy. In these studies, the effects of age, gender, smoking and alcohol use, previous radiotherapy, tumor characteristics, prior tracheotomy, accompanying systemic disease, pre- and postoperative hemoglobin levels, postoperative platelet levels, preoperative albumin levels, and erythrocyte transfusions were investigated (4-8). In the present study, we evaluated the difference between nutrition with a NGT and $\mathrm{OF}$ and found no difference in terms of PCF formation between the two groups despite the significant difference in preoperative albumin levels between the groups. Morton et al. (9) and Mattioli et al. (2) emphasized the important relationship between albumin and PCF in their studies. Our results indicated the effect of low preoperative albumin level on PCF formation. We will evaluate this factor in a larger patient group in future studies.

Some surgeons prefer delaying OF to prevent development of a fistula. The effect of early OF on the possibility of fistula de-

Table 1. Patient characteristics

\begin{tabular}{|c|c|c|c|}
\hline Variables & $\begin{array}{c}\text { Number of } \\
\text { patients with NGT }\end{array}$ & $\begin{array}{c}\text { Number of } \\
\text { patients with OF }\end{array}$ & $\mathrm{p}$ \\
\hline Gender & & & 0.476 \\
\hline Male & $28(93.33 \%)$ & $31(96.87 \%)$ & \\
\hline Female & $2(6.66 \%)$ & $1(3.22 \%)$ & \\
\hline Age & $61.46+7.52$ & $61.81+9.65$ & 0.878 \\
\hline Smoking & $30(100 \%)$ & $32(100 \%)$ & 1.00 \\
\hline Alcohol & $2(6.66 \%)$ & $3(9.37 \%)$ & 0.755 \\
\hline TNM-T stage & & & 0.875 \\
\hline $\mathrm{T} 2$ & $0(0 \%)$ & $2(6.25 \%)$ & \\
\hline T3 & $21(70 \%)$ & $24(75 \%)$ & \\
\hline $\mathrm{T} 4$ & $9(30 \%)$ & $6(18.75 \%)$ & \\
\hline TNM-N stage & & & 0.451 \\
\hline $\mathrm{N} 2 \mathrm{a}$ & $1(3.33 \%)$ & $0(0 \%)$ & \\
\hline $\mathrm{N} 2 \mathrm{~b}$ & $3(10 \%)$ & $2(6.25 \%)$ & \\
\hline $\mathrm{N} 2 \mathrm{c}$ & $22(73.33 \%)$ & $27(84.37 \%)$ & \\
\hline N3 & $4(13.33 \%)$ & $3(9.37 \%)$ & \\
\hline Preop $\mathrm{Hb}<12.2 \mathrm{~g} / \mathrm{dL}$ & $11(36.66 \%)$ & $16(50 \%)$ & 0.405 \\
\hline Postop $\mathrm{Hb}<12.2 \mathrm{~g} / \mathrm{dL}$ & $21(70 \%)$ & $20(62.5 \%)$ & 0.429 \\
\hline $\begin{array}{l}\text { Preop albumin } \\
<3.5 \mathrm{~g} / \mathrm{dL}\end{array}$ & $23(76.66 \%)$ & $28(87.5 \%)$ & 0.001 \\
\hline $\begin{array}{l}\text { Postop thrombocyte } \\
<130 \mathrm{~K} / \mathrm{mL}\end{array}$ & $3(10 \%)$ & $3(9.37 \%)$ & 0.533 \\
\hline Erythrocyte transfusion & $6(20 \%)$ & $8(25 \%)$ & 0.744 \\
\hline Previous tracheotomy & $4(13.33 \%)$ & $7(21.87 \%)$ & 0.448 \\
\hline Co-morbid illness & $10(33.33 \%)$ & $12(37.5 \%)$ & 0.886 \\
\hline Previous radiotherapy & $2(6.66 \%)$ & $2(6.25 \%)$ & 0.890 \\
\hline
\end{tabular}

NGT: nasogastric tube; OF: oral feeding; Preop: preoperative; Postop: postoperative 
Table 2. Relationship between feeding approach and PCF

\begin{tabular}{l|c|c|c} 
& Patients with NGT & Patients with OF & $p$ \\
\hline Number of PCF & $5(16.66 \%)$ & $6(18.75 \%)$ & 0.929 \\
\hline $\begin{array}{l}\text { Duration of } \\
\text { hospitalization (days) }\end{array}$ & $16.43+11.60$ & $12.87+7.22$ & 0.125 \\
\hline
\end{tabular}

NGT: nasogastric tube; OF: oral feeding; PCF: pharyngocutaneous fistula

velopment remains controversial (10). Starting oral nutrition during the early phase is accepted as playing a role in the development of PCF. On the other hand, a NGT causes local trauma and significantly increases stress on the pharyngeal suture line, and this stress may result in the formation of a fistula. It has been thought that applying a NGT can damage the pharyngeal mucosa primarily via acidic gastroesophageal reflux (11). PCF vary from $1 \%$ to $50 \%$ in patients with total laryngectomy fed with a NGT $(12,13)$. In our study, we detected a PCF in $16.66 \%$ of patients in whom feeding with a NGT was started on postoperative day one.

No other studies observed any relationship between the formation of fistulae and starting OF early. Akyol et al. (14) observed PCFs in $21 \%$ of patients who received a total laryngectomy and who received an early oral diet (water and clear fluids) on postoperative day one. Aprigliano (15) reported a 9\% incidence of $\mathrm{PCF}$ in patients who underwent a total laryngectomy and to whom oral nutrition was started on postoperative day three. We determined that $18.75 \%$ of fistulas developed in patients who had started OF on postoperative day three. A NGT can cause several complications, such as permanent nasal alar deformity, acute sinusitis, pneumothorax, aspiration pneumonia, gastroesophageal reflux, and persistent dysphagia. In addition, a NGT can cause additional stress on the suture line during the postoperative period and contribute to the development of a PCF $(14,16,17)$.

Sharifian et al. (18) found no significant difference between nutrition with a NGT for the first 7 days and OF on day 3 in patients who had PCF after total laryngectomy. They also reported that the PCF could be completely closed with compressive dressings. In consistent with previous studies, our patients with PCF healed well with compressive dressings in both groups.

\section{Conclusion}

Starting OF on postoperative day three did not influence the formation of PCF and hospital stay after total laryngectomy. Therefore, we recommend early OF after total laryngectomy. It is necessary to investigate the effect of albumin level on the development of PCF after total laryngectomy in larger groups of patients.

Ethics Committee Approval: Ethics committee approval was received for this study from the Ethics Committee of Tepecik Training and Research Hospital (Date: 7/03/2017, No: 2/7).
Informed Consent: Written informed consent was obtained from patients who participated in this study.

Peer-review: Externally peer-reviewed.

Author Contributions: Concept - S.B., İ.Ç.; Design - S.B., İ.Ç.; Supervision - S.B., İ.Ç.; Resource - S.B., İ.Ç.; Materials - S.B., İ.Ç.; Data Collection and/or Processing - S.B., İ.Ç.; Analysis and/or Interpretation S.B., I.Ç.; Literature Search - S.B., İ.Ç.; Writing - S.B.; Critical Reviews - S.B., İ.Ç.

Conflict of Interest: The authors have no conflicts of interest to declare.

Financial Disclosure: The authors declared that this study has received no financial support.

\section{References}

1. Erdag MA, Arslanoglu S, Onal K, Songu M, Tuylu AO. Pharyngocutaneous fistula following total laryngectomy: multivariate analysis of risk factors. Eur Arch Otorhinolaryngol 2013; 270: 173-9. [CrossRef]

2. Mattioli F, Bettini M, Molteni G, PiccininiA, Valoriani F, Gabriele $\mathrm{S}$, et al. Analysis of risk factors for pharyngocutaneus fistula after total laryngectomy with particular focus on nutritional status. Acta Otorhinolaryngol Ital 2015; 35: 243-8.

3. Süslü N, Şefik Hoşal A. Early oral feeding after total laryngectomy: Outcome of 602 patients in one cancer center. Auris Nasus Larynx 2016; 43: 546-50. [CrossRef]

4. Paydarfar JA, Birkmeyer NJ. Complications in head and neck surgery: a meta-analysis of postlaryngectomy pharyngocutaneous fistula. Arch Otolaryngol Head Neck Surg 2006; 132: 67-72. [CrossRef]

5. Galli J, De Corso E, Volante M, Almadori G, Paludetti G. Post laryngectomy pharyngocutaneous fistula: incidence, predisposing factors, and therapy. Otolaryngol Head Neck Surg 2005; 133: 68994. [CrossRef]

6. Boscolo-Rizzo P, De Cillis G, Marchiori C, CarpenèS, Da Mosto MC. Multivariate analysis of risk factors for pharyngocutaneous fistula after total laryngectomy. Eur Arch Otorhinolaryngol 2008; 265: 929-36. [CrossRef]

7. Dedivitis RA, Ribeiro KC, Castro MA, Nascimento PC. Pharyngocutaneous fistula following total laryngectomy. Acta Otorhinolaryngol Ital 2007; 27: 2-5.

8. van Bokhorst-de van der Schueren MA, van Leeuwen PA, Sauerwein HP, Kuik DJ, Snow GB, Quak JJ. Assessment of malnutrition parameters in head and neck cancer patients and their relation to postoperative complications. Head Neck 1997; 19: 419-25. [CrossRef]

9. Morton RP, Fielder CP, Dorman EB. Prediction and prevention of fistulae after major head and neck surgery: a preliminary report. Aust N Z J Surg 1988; 58: 951-3. [CrossRef]

10. Virtaniemi JA, Kumpulainen EJ, Hirvikoski PP, Johansson RT, Komsa VM. The incidence and etiology of postlaryngectomy pharyngocutaneous fistulae. Head Neck 2001; 23: 29-33. [CrossRef]

11. Saydam L, Kalcioglu T, Kizilay A. Early oral feeding following total laryngectomy. Am J Otolaryngol 2002; 23: 277-81. [CrossRef]

12. Makitie AA, Niemensivu R, Hero M, Keski-Säntti H, Bäck L, Kajanti M, et al. Pharyngocutaneous fistula following total laryn- 
gectomy: a single institution's 10-year experience. Eur Arch Otorhinolaryngol 2006; 263: 1127-30. [CrossRef]

13. Soylu L, Kiroglu M, Aydogan B, Cetik F, Kiroglu F, Akçali C, et al. Pharyngocutaneous fistula following laryngectomy. Head Neck 1998; 20: 22-5. [CrossRef]

14. Akyol MU, Ozdem C, Celikkanat S. Early oral feeding after total laryngectomy. Ear Nose Throat J 1995; 74: 28-30.

15. Aprigliano F. Use of nasogastric tube after total laryngectomy: is it truly necessary? Ann Otol Rhinol Laryngol 1990; 99: 513-4. [CrossRef]
16. Seven $\mathrm{H}$, Calis $\mathrm{AB}$, Turgut $\mathrm{S}$. A randomized controlled trial of early oral feeding in laryngectomized patients. Laryngoscope 2003; 113: 1076-9. [CrossRef]

17. Paydarfar JA, Birkmeyer NJ. Complications in head and neck surgery: a meta-analysis of postlaryngectomy pharyngocutaneous fistula. Arch Otolaryngol Head Neck Surg 2006; 132: 67-72. [CrossRef]

18. Sharifian HA, Najafi M, Khajavi M. Early oral feeding following total laryngectomy. Tanaffos 2008; 7: 64-70. 